\title{
Polycyclic Aromatic Hydrocarbons (PAHs) and their Derivatives (O-PAHs, N-PAHs, OH-PAHs): Determination in Suspended Particulate Matter (SPM) - a Review
}

\author{
M. Nowakowski ${ }^{1}$ (D. I. Rykowska ${ }^{2} \cdot$ R. Wolski ${ }^{3} \cdot$ P. Andrzejewski ${ }^{1}$
}

Received: 21 July 2021 / Accepted: 13 November 2021 /Published online: 29 December 2021

(c) The Author(s) 2021

\begin{abstract}
The aim of this paper is the presentation of the current state-of-the-art about the determination of polycyclic aromatic hydrocarbons (PAHs) and their oxidized forms originating from Suspended Particulate Matter (SPM) samples. The influence of SPM on health is twofold. SPM, as composed of small particles, is dangerous for the respiratory system. Additionally, SPM is a carrier of many hazardous compounds, particularly PAHs. Recently, several researches focus on the derivatives of PAHs, particularly nitro-, oxy- and hydroxy-PAHs, which are more dangerous than the parent PAHs. Both gas and high-performance liquid chromatography with various detection techniques are used to analyze both PAHs and their oxidized forms. Due to the appearance of these compounds in the environment, at a very low level, an analyte concentration step has to be applied prior to analysis. If GC and HPLC techniques are chiefly used as analytical tools for these analyses, the spectrum of analyte concentration procedures is very broad. Many analyte concentration techniques are proposed: from classic liquid-solid extractions, including Soxhlet technique, pressurized liquid extraction (ASE) or microwave oven (MWE) and sonic supported extraction to SPE techniques applications. However, one should remember that PAH determination methods are tools for solving the main problem, i.e., the evaluation the health hazard connected to the presence of SPM in air. Thus, the main drawback of several papers found in this review, i.e., the lack of information concerning limit of detection (LOD) of these methods makes their applicability very limited.
\end{abstract}

Keywords PAHs · nitro-PAHs · oxy-PAHs · Analytical procedures for PAHs · Air pollution $\cdot$ SPM

M. Nowakowski

micnow2@amu.edu.pl

1 Faculty of Chemistry, Department of Trace Analysis, Adam Mickiewicz University in Poznan, 8 Uniwersytetu Poznańskiego St, Poznan 61-614, Poland

2 Faculty of Chemistry, Department Analytical Chemistry, Adam Mickiewicz University in Poznan, 8 Uniwersytetu Poznańskiego St, Poznan 61- 614, Poland

3 Faculty of Chemistry, Department of Applied Chemistry, Adam Mickiewicz University in Poznan, 8 Uniwersytetu Poznańskiego St, Poznan 61- 614, Poland 


\section{Introduction}

Smog is a serious problem in many cities all over the world (Musa Bandowe et al. 2019). The word 'smog' comes from a combination of two English words - smoke and fog (Schwartz Cowan 1997). This is an unnatural phenomenon, formed mainly due to windless weather - artificial fog composed of residues after incomplete combustion of many types of fuels (Abbasi and Keshavarzi 2019). The main component of smog is suspended particulate matter, defined as aerosols of liquid drops or solid particles. Suspended particulate matter can be of natural origin (e.g., sea salt) or anthropogenic (e.g., dust from fuel combustion processes) (Reizer 2016). In the second case, Suspended Particulate Matter (SPM) is a measure of the air contamination. The size can classify SPM. Dust with particle diameter less than $10 \mu \mathrm{m}$ is called PM10, and with particle diameter less than $2.5 \mu \mathrm{m}$, PM2.5. Many studies also mentioned PM4 with particle diameter $4 \mu \mathrm{m}$ and PM1 with particle diameter $1 \mu \mathrm{m}$ (Kic 2018; Boac et al. 2009).

The influence of SPM on health is twofold. Tiny particles of SPM can be dangerous for the respiratory system. The PM10 fraction is called the 'chest fraction' because of presenting danger on chest organs - heart, bronchi (Brown et al. 2013). Much smaller PM2.5 can penetrate pulmonary alveoli, and is called 'respiratory fraction' (Boldo et al. 2006). The SPM is also a carrier of many hazardous compounds, formed in the incomplete combustion of many types of fuel processes. Heavy metal (e.g., cadmium, nickel) are adsorbed mainly on PM2.5 (Deng et al. 2006). They can penetrate the blood and can cause diseases typical of exposure to these metals.

Polycyclic aromatic hydrocarbons (PAHs) are among the substances that receive particular attention. PAHs are also adsorbed on suspended particulate matter. PAHs are a group of more than 10,000 compounds (Kurnia et al. 2018). PAHs can be divided by their molecular weight into low molecular weight (LMW) and high molecular weight (HMW) subtypes. LMW PAHs form a group of compounds with two- or three-ring structure, while HMW PAHs contain four or more rings (Saldarriga-Noena et al. 2018). Many studies report their carcinogenicity (Hayakawa 2018; IARC 2016), toxicity (Bandowe et al. 2019) and mutagenicity (Bandowe et al. 2014; Umbuzeiro et al. 2008) functions. The carcinogenic properties of PAHs increase with increasing molecular weight. While HMW PAHs are more carcinogenic, LMW PAHs are characterized by increased toxicity (Kim et al. 2013). For various reasons, the United States Environmental Protection Agency (USEPA) lists 16 compounds belonging to the PAH group as recommended for environmental monitoring (Keith 2014; USEPA 2008); however, the number of PAHs which are present in the air cause more danger (Mueller et al. 2019). Furthermore, these compounds can be converted into much more toxic oxidized forms of PAHs, when the conditions are favorable (Mueller et al. 2019; Ringuet et al. 2012). Nitro- and oxy-PAHs are suspected to be more toxic than parent forms due to their direct action as mutagens, but the level of knowledge about the carcinogenicity of these compounds is still under study (de Oliveira Galvao et al. 2018). Also, the acute toxicity is different for the original PAHs and their derivatives. For example, the $\mathrm{LD}_{50}$ for fluorene is $16,000 \mathrm{mg} / \mathrm{kg}$ (rat, oral), while for nitrofluorene it is $1,600 \mathrm{mg} / \mathrm{kg}$ (Zaciera 2007).

Particulate matter (PM) has become a major research issue receiving increasing attention because of its significant negative impact on human health. Besides the particle's morphological characteristics, the chemical composition plays an important role on adverse health effects of PM (Walgraeve et al. 2010). Most of the PAHs with low vapor pressure in the air are adsorbed on PM particles, due to the fact that even though PAHs show low 
solubility in water, they are highly lipophilic. When dissolved in water or adsorbed on particulate matter, PAHs can undergo photodecomposition when exposed to ultraviolet light from solar radiation. In the atmosphere, PAHs can react with pollutants such as ozone, nitrogen oxides, and sulfur dioxide, yielding diones, nitro- and dinitro-PAHs, and sulfonic acids, respectively. PAHs may also be degraded by some microorganisms in the soil (Srogi 2007). Table 1 presents a review of publications presenting the latest developments in the determination of PAHs in particulate matter.

As it may be seen while analyzing the table, recently many qualitative and quantitative studies of PAHs in various environmental matrices have been successfully carried out. Nevertheless, this type of analysis still presents many problems, especially at the stage of sample preparation. Due to the widely varying physical and chemical properties of PAHs, their measurement is often difficult and costly. Methodology for sampling, analysis, and emission estimation will need to be harmonized in order to properly assess current ambient concentrations, the effect of future control measures, and to refine any further action which may be required to adequately assess their human health impacts. Therefore, continuous research is needed to improve the current methods and their technical parameters.

The table above summarized the latest progress in this domain. The table data are focused on recent advances in PAH extraction techniques from environmental matrices, utilizing novel sample preparation approaches and adsorbents. Most of the novel extraction techniques are variations of the conventional SPE approach; however, liquid-liquid extraction (LLE) based approaches have also been reported. A lot of progress has been made in the field of sorbent development for micro and miniaturized SPE sample preparation techniques. Metal-organic frameworks, covalent organic frameworks, zeolitic imidazole frameworks, graphene, graphene oxide and carbon nanotubes are some typical examples of novel extraction sorbents that have been implemented as such, or after surface modification for the extraction of PAHs from environmental samples. At the same time, ionic liquids, polymeric ionic liquids and deep eutectic solvents have been implemented in liquid phase microextraction approaches as extraction solvents and in solid-phase extraction approaches for the surface modification of a plethora of adsorbents (Manousi and Zachariadis 2020; Nascimento et al. 2019; Jiping et al. 2020).

The selection of the extraction technique, as well as the extraction sorbent can be based on the needs of the analysis (e.g., selectivity) and the laboratory equipment. Matrix solid phase extracton (MSPE) and dispersive solid phase extraction (d-SPE) are some examples of simple, rapid and environmentally friendly extraction procedures, that have recently gained a lot of attention, due to their convenience in sample handling. The application of these techniques has rapidly increased, and a wide variety of sorbents have been evaluated. Other novel miniaturized extraction forms, including SBSE, PT-SPE and FPSE have also become popular during the last years. These techniques have been evaluated in less extend compared to SPE, MSPE and d-SPE methods; however, due to their ease in operation, they are considered useful alternatives that enrich the toolbox of analytical chemists (Sun et al. 2020; Lisowski and Zarzycki 2013).

Recently, the research on new analytical techniques for the trace nitro-PAHs took special attention (Sun et al. 2020). As the sample matrix is complex and the nitro-PAHs are at trace levels in the samples, the requirements for sample treatment are very high. Many novel adsorption materials such as carbon nanotubes / magnetic carbon nanotubes, graphene oxide, aptamers, molecularly imprinted polymers (MIPs), electro spun nanofibers, and many newly emerging extraction solvents including ionic liquids, supramolecular solvents, and deep eutectic solvents have good application prospects in the extraction of trace nitro-PAHs in the various samples because of their environmentally friendly and 


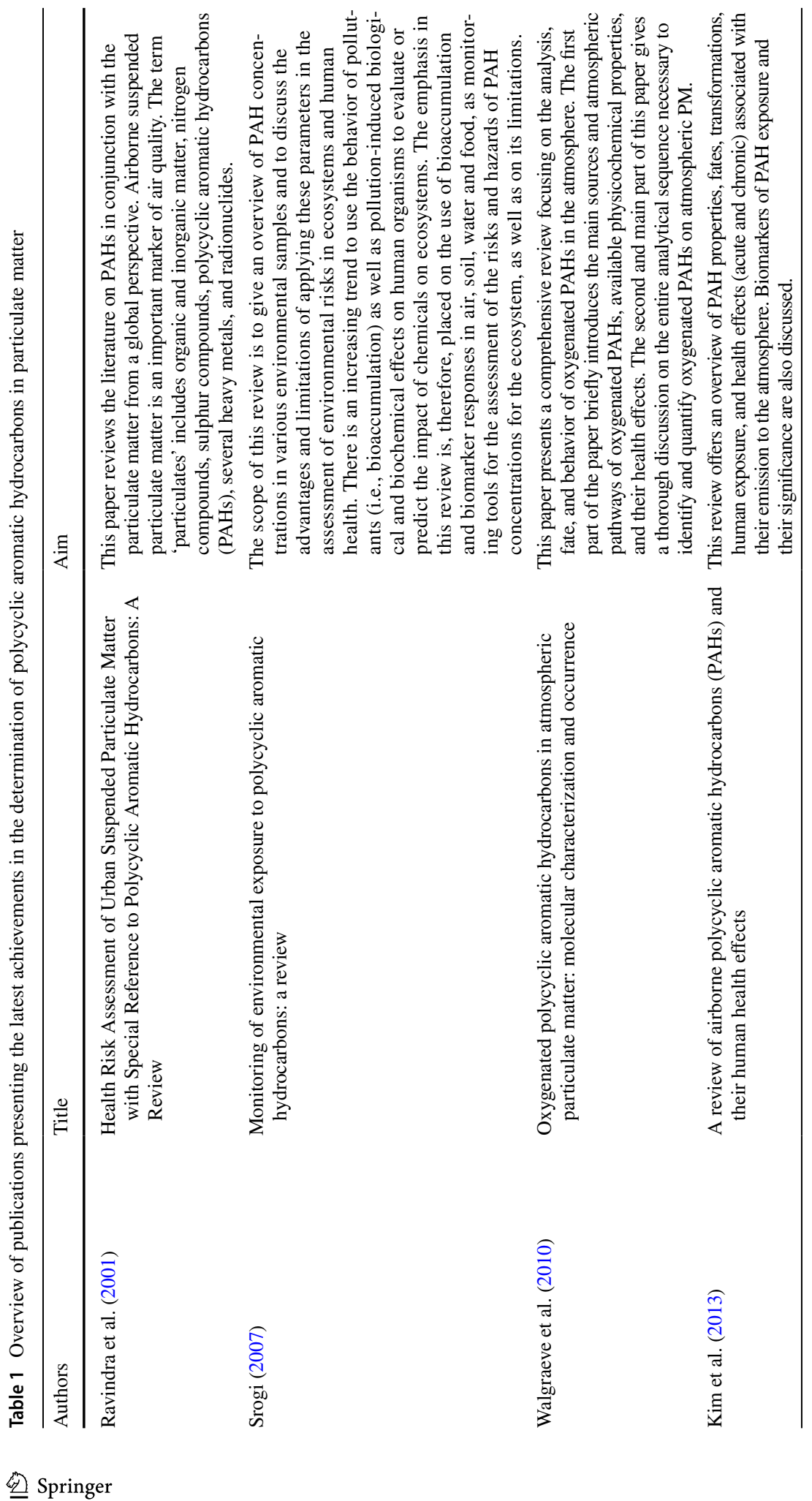




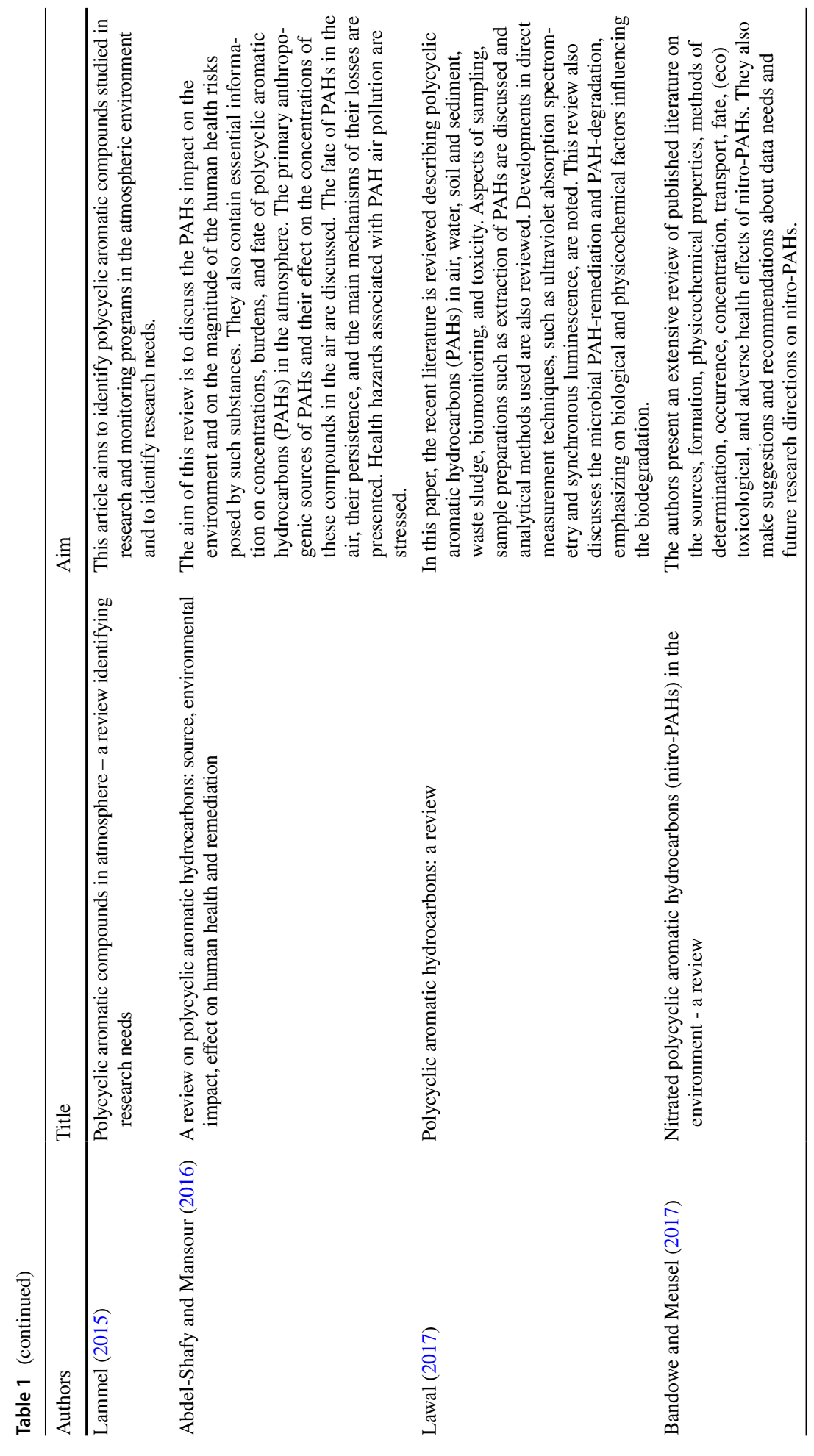




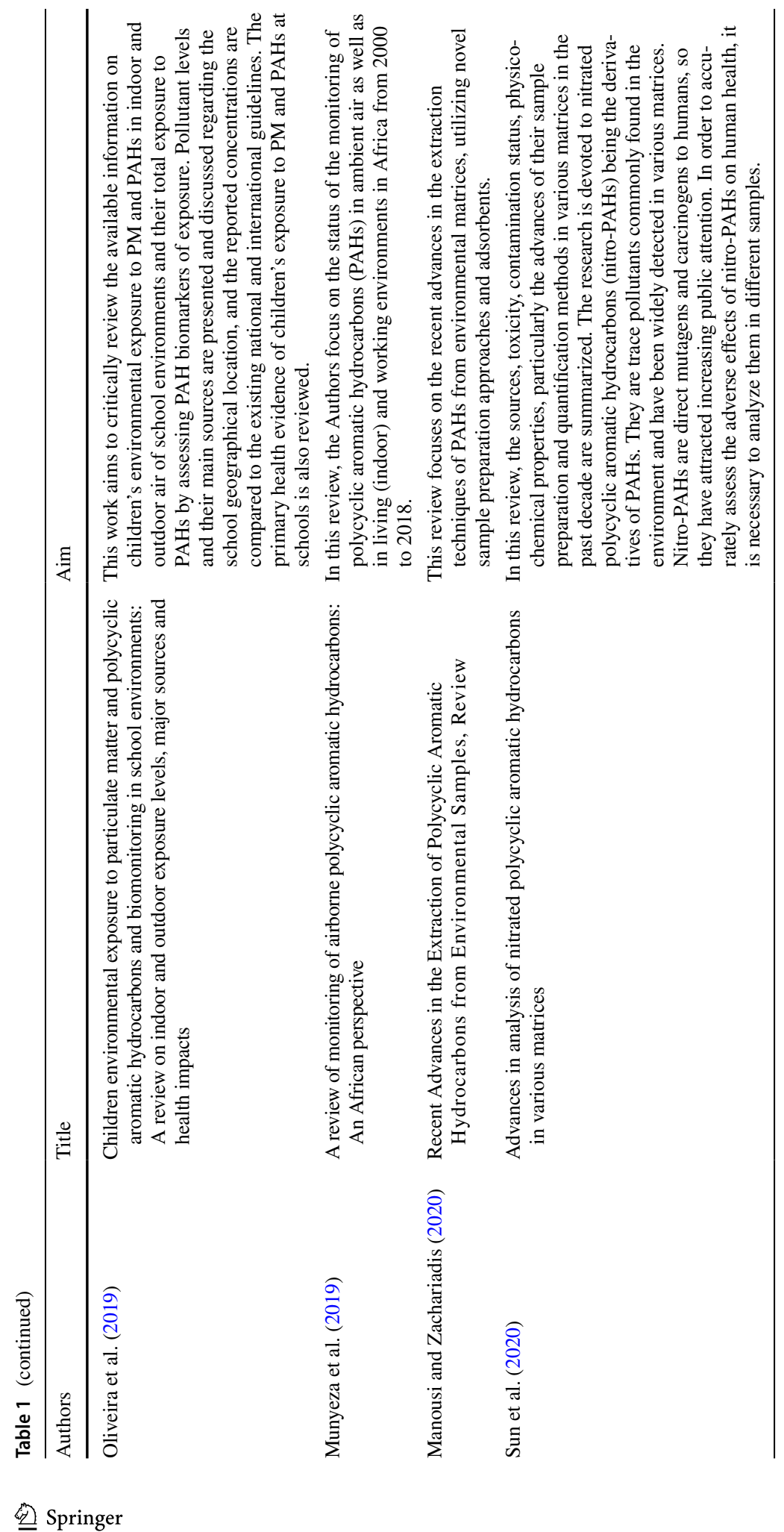


non-toxic or low toxic features, their low cost, and their easy availability. There is an increasing interest in various miniaturized systems like microfluidic paper-based analytical device (m-PAD), micro total analysis system (m-TAS), surface-enhanced Raman scattering (SERS) devices, surface plasmon resonance (SPR) system, and other miscellaneous biosensors, as well as electric-field driven separation devices including diverse forms of electrophoresis and microchip capillary electrophoresis. All these techniques have potential applications in the future for nitro-PAHs analysis, especially in their real-time or on-site analysis (Yang et al. 2019; Kaneta et al. 2018).

The aim of this paper is a presentation of the current state-of-the-art about the determination of PAHs and their oxidized forms originating from Suspended Particulate Matter samples.

\section{PAHs and their Oxidized Forms}

PAHs are a group of compounds, which contain condensed aromatic rings. It is a group of more than 10,000 compounds, but the National Institute of Standard and Technology (NIST) reported 660 structural formulas of PAHs in NIST Special Publication 922/2011 (Kubiak 2013). PAHs are formed by incomplete combustion of many types of fuels, particularly diesel fuel (Abbasi and Keshavarzi 2019). When they are adsorbed on suspended particulate matter, they are one of the main components of smog. Many studies report their harmful impact on human health.

PAHs in the human body are converted in reaction with cytochrome P450 into phenols and dihydrodiols. Then, part of dihydrodiol is converted by additional oxidation into dihydrodiol epoxides (Moorthy et al. 2015). The metabolites of PAH have been determined as biomarkers to evaluate the exposure of humans to PAHs. The urinary 1-hydroxypyrene has been used as a biological indicator for evaluating exposure. The presence of PAHs metabolites (1-hydroxypyrene and naphthol) was identified in the wastewater effluent amongst anti-androgenic chemicals (Rostkowski et al. 2011). The routes of intake of nitro-PAHs by humans and animals from the environment are inhalation, oral ingestion, and dermal contact. Several test systems, e.g., bacterial strains (Ames test using Salmonella), mammalian and fish cell lines, biological molecules (DNA) plants and rats and mouses in-vivo studies have been used to study the carcinogenicity, mutagenicity/genotoxicity of nitroPAHs in environmental media (soil, sediments, atmospheric particulates (Abbas et al. 2018). According to scientific studies and the International Agency for Research on Cancer (IARC) Working Group on the Evaluation of Carcinogenic Risks to Humans, several nitro-PAHs have been classified into carcinogenic groups (Bandowe and Meusel 2017). The level of toxicity of some nitro-PAHs was determined as much higher than the level of toxicity of benzo[a]pyrene (Collins et al. 1998).

Both the USEPA and the European Environmental Agency recognize the necessity of monitoring the content of PAHs in the air. Benzo[a]pyrene was adopted in the $1980 \mathrm{~s}$ as a standard compound in air quality monitoring and research, as a determinant of mischievousness. Already in the 90 s many studies were conducted in which the concentration of PAHs in the air was determined. The concentration of PAHs and benzo[a]pyrene strongly depended on the sampling sites (urban, rural, industrial, traffic air).

Sapota (Sapota 2002) pointed out that the recommendations of American and European agencies are different - the American one recommends detailed analysis of all 16 priority PAHs, and the European agency recommends the measurement of benzo[a]pyrene only. 
Recently, more research focused on oxidized forms of PAHs - nitro-, oxy- and hydroxyderivatives. New research also mentions that heterocyclic thio-PAHs are noteworthy compounds (Bandowe and Meusel 2017). Many studies describe the toxicity of oxidized PAH forms as higher than the non-substituted PAHs (de Oliveira Galvao et al. 2018; Bandowe and Meusel 2017; Idowu et al. 2019). The derivatives of PAHs can be formed in two ways. One is a primary emission from combustion processes. The second way is the photochemical reactions between PAHs and other contamination (nitrogen oxides, sulfur oxides) or ozone in the atmosphere (Cordeiro and Corio 2009; Drotikova et al. 2020). Some forms of nitro-derivatives of PAHs are indicator products of certain chemical transformations (Mulder et al. 2019). But in contrast to PAHs, there are no regulations about PAH derivative concentrations in the environment. Only Swedish and Danish environmental protection agencies included nitro-PAHs in their environmental monitoring studies (BrorströmLunden et al. 2008) and California EPA lists several nitro-PAHs which should be regularly monitored (OEHHA 2005). Oxy- and nitro-PAHs are not included in existing monitoring programs (Lammel et al. 2020). Additionally, the occurrence of PAH derivatives can provide information about parent PAH sources alongside methods such a chemical mass balance (CMB) or isomer ratio analysis (Ozaki et al. 2020). Figure 1 shows possible ways of oxidation or nitration on the example of pyrene and benzo[a]pyrene.

The main problem is the lack of sufficiently sensitive methods of tracking the course of PAH reactions in the atmosphere (Lammel 2015). Reactions between PAHs and different

a)<smiles>c1cc2ccc3cccc4ccc(c1)c2c34</smiles>

b)

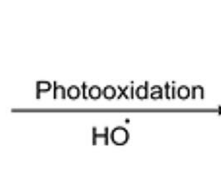

1,8-pyrene-dione

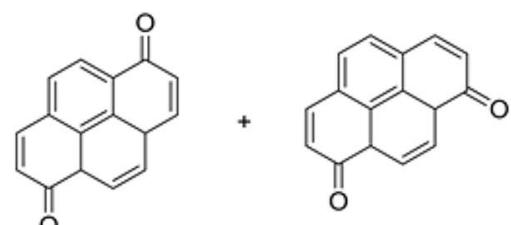

1,6-pyrene-dione<smiles>C1=CC2C=CCc3c4ccccc4cc4ccc(c2c34)C1</smiles><smiles>O=[N+]([O-])C1C2CC3CC(C2)C([N+](=O)[O-])C([N+](=O)[O-])C1C3</smiles><smiles></smiles><smiles>CCCC</smiles><smiles>O=[N+]([O-])C1C=c2ccc3c4ccccc4cc4ccc(c2c43)C1O</smiles><smiles>CCC(C)[N+](=O)[O-]</smiles><smiles>CC1Cc2ccc3cc4ccccc4c4ccc(c2c34)=CC1[N+](=O)[O-]</smiles><smiles>O=[N+]([O-])C1C=c2ccc3c4ccccc4cc4ccc(c2c43)C1[N+](=O)[O-]</smiles><smiles></smiles>

Fig. 1 a) Possible way of photochemical oxidation of pyrene. b) Different ways of nitration and oxidation of PAHs (adapted from Lu et al. 2011). (adapted from Cordeiro and Corio 2009) 
radicals in the atmosphere can occur both with and without sunlight. Figure 2 shows ways of PAH transformation (example of naphthalene).

\section{Sample Preparation and Analytical Procedures for PAHs and Derivatives Originating from SPM}

A majority of PAHs and their oxidized forms can be analyzed by the same analytical techniques. Figure 3 shows the scheme of determination of PAHs and their derivatives.

\subsection{PAHs}

The sampling may be performed with a variety of samplers, both low- and high-volume sampling rates and even passive samplers. Sampling media include quartz fiber, glass fiber, Teflon-coated glass fiber, and Teflon membrane filters (Szulejko et al. 2014). Glass and quartz fiber filters (GFF and QFF) are mainly annealed at high temperatures (400-550 ${ }^{\circ} \mathrm{C}$ ) for several hours to lower blank levels associated with the new filters and weighed before the sampling. The previously weighed filters are reweighed after sample collection; then, the filters are protected and stored at a temperature below $15{ }^{\circ} \mathrm{C}$. The generally used technique is gas chromatography with mass spectrometry (GC/MS), but (ultra)high performance liquid chromatography ((U)HPLC) with the reversed-phase system is also used (Singh et al. 2019). Fluorescence detectors, diode arrays, and mass spectrometry are the most often used detectors. Detailed conditions for GC/MS analysis are given by Mueller et al. (2019). They used GC/MS to analyze 64 PAHs and their derivatives, achieving a low limit of detection (LOD). They proposed using methane as a chemical ionization, helium as a quench gas, and nitrogen as the collision gas. Their

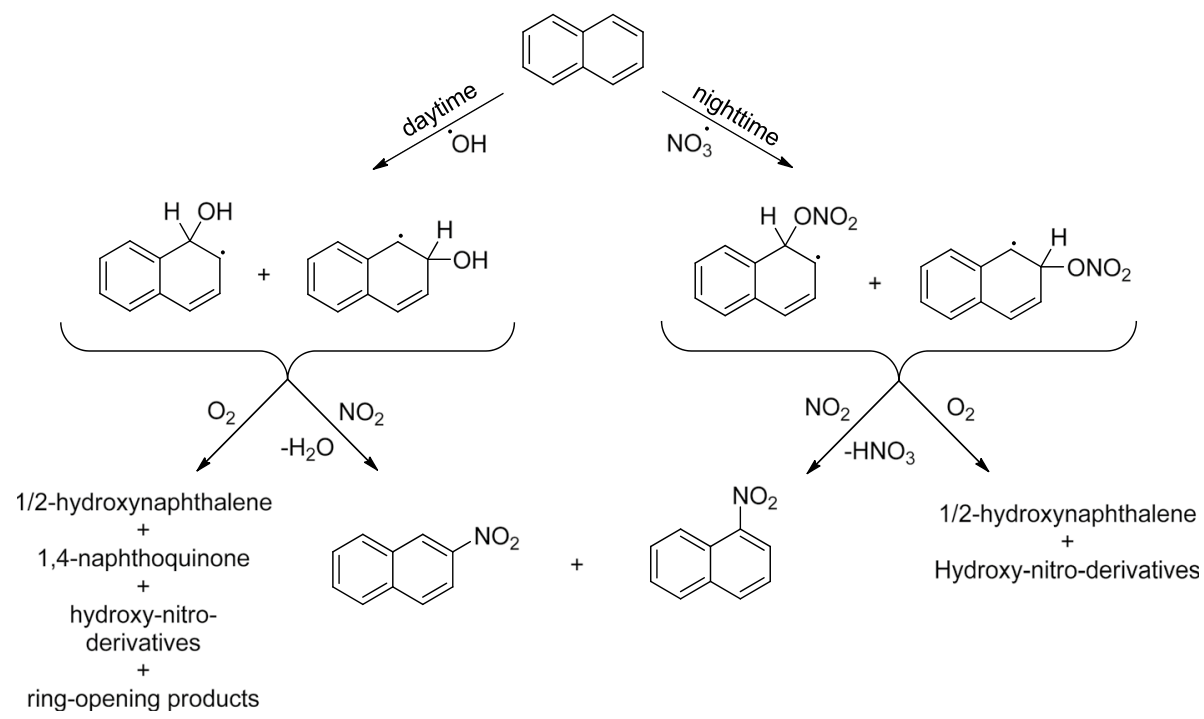

Fig. 2 Reactions of naphthalene with atmospheric radicals during day- and nighttime. (adapted from Vione et al. 2004) 


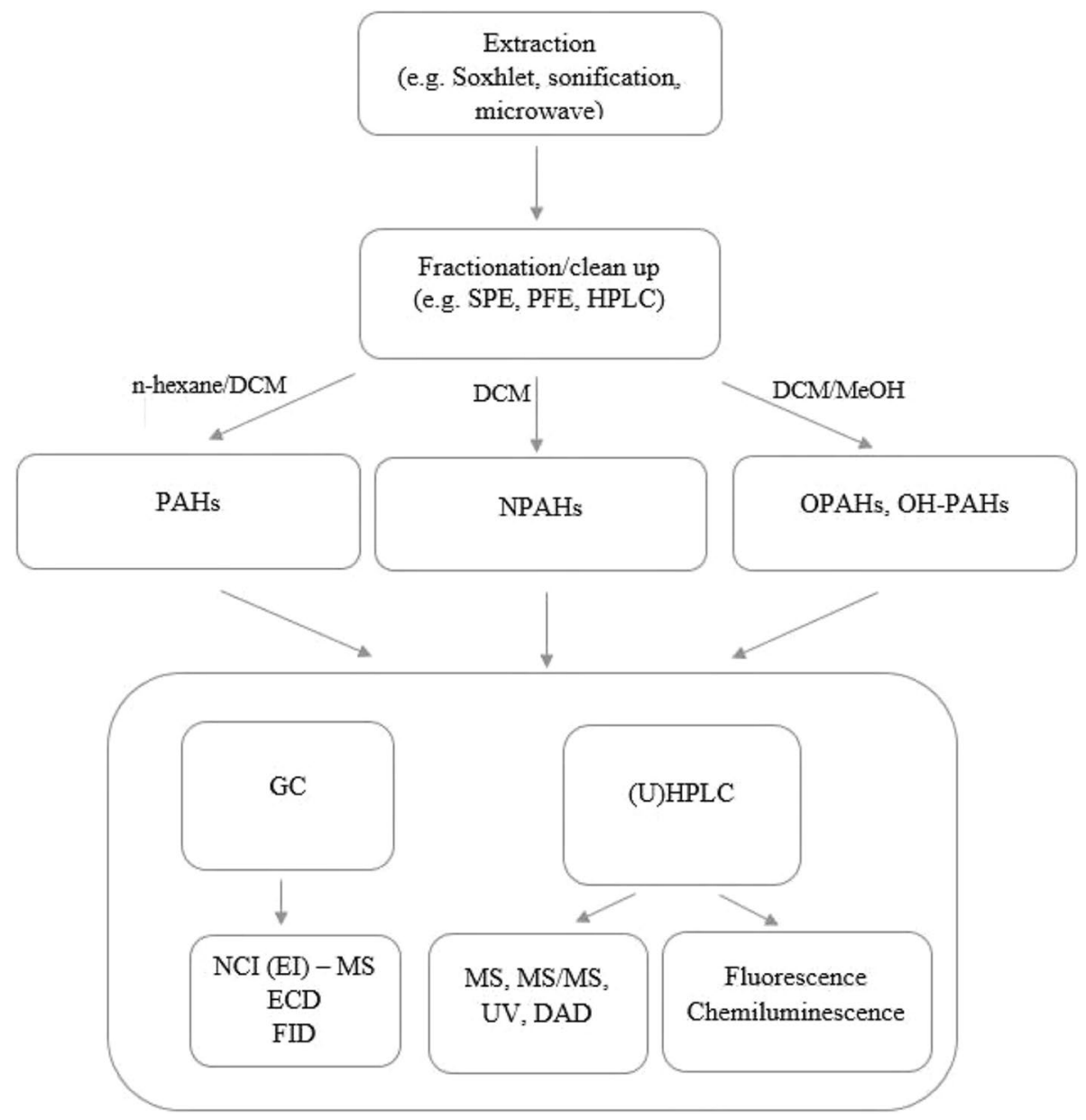

Fig. 3 Determination of PAHs and their derivatives. (adapted from Bandowe and Meusel 2017)

total run time was $47.45 \mathrm{~min}$, with a selected temperature program. Also, Mulder et al. (2019) present a well-described analytical procedure using GC/MS. Wilson et al. (2017) suggest using normal-phase liquid chromatography with aminopropyl stationary phase. Some differences can be observed in the sample preparation processes. Barrado et al. (2012; 2013) used extraction with microwave oven (MWE) following a 40-min program with temperature gradation to final temperature of $120{ }^{\circ} \mathrm{C}$ and power range of $900 \mathrm{~W}$. They proposed using dichloromethane as an extraction solvent. The efficiency of this process was reported as exceeding 80\%. Crimmins and Baker (2006) proposed sonic supported extraction. Samples were sonicated for $30 \mathrm{~min}$ in dichloromethane and then stored for $48 \mathrm{~h}$ at $-20{ }^{\circ} \mathrm{C}$. After that, the extract was evaporated to $200 \mu \mathrm{L}$ under nitrogen flow. The samples were analyzed by the GC/MS. Jakovljević et al. (2018) used extraction with a mixture of toluene-cyclohexane (7:3) in a sonic bath. Then, the samples were evaporated to dryness and re-dissolved in acetonitrile. The samples were analyzed by HPLC with fluorescence detector. Umbuzeiro et al. (2008) used dichloromethane in Soxhlet extraction. Similar procedures are described by Lammel et al. (2020). This 
process lasted for $20 \mathrm{~h}$ at $40{ }^{\circ} \mathrm{C}$. After extraction, the solvent was evaporated to almost dryness and the sample was re-dissolved in a small amount of dichloromethane.

Abbasi and Keshavarzi (2019) proposed a similar procedure. After Soxhlet extraction, they used silica gel column to pre-concentrate and clean-up extract, and then the extract was fractionated to 4 fractions with different polarities. Almost identical procedure was proposed by Mulder et al. (2019) except that dichloromethane and acetone/hexane (1:1) were used for extraction. Albinet et al. (2006) proposed using pressurized liquid extraction (ASE) with dichloromethane as a solvent. Samples were supplemented with chemical standards and twice extracted by ASE, and then dried under $\mathrm{Na}_{\mathrm{a}} \mathrm{SO}_{4}$. Similar procedure was used by Wilcke et al. (2014), and then by Bandowe et al. (2014). Oleagoitia et al. (2019) extracted PAHs with a microwave and acetonitrile as a solvent. (U)HPLC with ultraviolet and fluorescence detection was used as an analytical technique. Han et al. (2019) proposed a similar procedure of sample extraction, and then they fractionated the extract of the PAHs, nitro-PAHs, oxy-PAHs and OH-PAHs using SPE cartridges. PAHs are eluted by a mixture of $\mathrm{n}$-hexane and dichloromethane (ratio 1:1 v/v). This fraction contains beyond PAHs also nitro- and oxy-PAHs. GC-EI-MS were used to determine PAHs. Comparison of the most frequently used sampling and analytical methods for PAHs is given in the summarizing table after the Section 3.1-3.3.

\subsection{Nitro-PAHs}

Samples for PAHs and nitro-PAHs analyses can be collected simultaneously using the methods described earlier for PAHs. Nitro-PAHs, as well as the other PAHs, can be analyzed by the GC or (U)HPLC coupled with different detectors. Various methods of ionization can be used: negative ion chemical ionization (NICI), electron impact (EI), atmospheric pressure ionization (APCI), atmospheric pressure photo-ionization (APPI) with instruments operated in selective ion monitoring (SIM), or multiple reaction monitoring mode (MRM). Fluorescence, chemiluminescence and photodiode array detection methods can be used besides mass spectroscopy. Considering that nitro-PAHs can decompose at higher temperatures, Sun et al. (2020) point out that HPLC analysis is a better method for nitro-PAH analysis. Regardless of the method of determination, the most important element is the preparation of samples, taking into account the low levels of nitro-PAH concentrations. Zhao et al. (2020a) describe exactly the procedure of sample preparation. They extracted sample filters with dichloromethane by Soxhlet at $45^{\circ} \mathrm{C}$. Next, the samples were evaporated to about $1 \mathrm{~mL}$ and purified through a column with silica gel and alumina. Then, the samples were eluted by a column with hexane and a mixture of hexane and dichloromethane $(\mathrm{DCM})(1: 1 \mathrm{v} / \mathrm{v})$. The eluates (hexane/DCM) were collected and evaporated again. Next, the samples were analyzed by CG/MS with electron impact ionization (EI).

Almost identical method was used by Zhao et al. (2020b). Oliveira Galvao et al. (2018) and Kitanovski et al. (2020) proposed using GC-MS to analyze both nitro- and oxy-PAHs. Also, Gao et al. (2018), Mueller et al. (2019) and dos Santos et al. (2019) presented a similar procedure. The possibility of measurements at a room temperature (where the nitro-PAHs are more stable) is the main advantage in using (U)HPLC in comparison to GC. C-18 Columns (Schauer et al. 2004; Mirivel et al. 2010; Nyiri et al. 2016) or phenylhexyl column (Garcia-Alonso et al. 2012) can be used for the separation of small, volatile molecules and large unstable molecules. Several different methods of sample preparation were presented. Zielinska and Sammy (2006) used the conventional method of sample preparation by Soxhlet extraction, sonication and pressurized fluid extraction (PFE). They 
mentioned dichloromethane, toluene, or benzene as the most commonly used solvents. PFE is a time saving, and easy to use method, with low consumption of the solvent. Bamford et al. (2003) and Ringuet et al. (2012) also prepared samples by means of PFE method. Simultaneous analysis of both PAHs and nitro-PAHs with the same procedure of the extraction by pressurized liquid extraction and dichloromethane as an extraction solvent was reported by Bandowe et al. (2014). Also, Han et al. (2019) proposed a determination of PAHs and nitro-PAHs from a single sample. In this research, GC-NICI-MS was applied for the determination of nitro-PAHs, while to determine the other PAHs the authors proposed a slighty different method. An efficient analysis of both PAHs and nitro-PAHs was also proposed by Pham et al. (2019). HPLC with fluorescence detector (HPLC-FL) was used as a basic analytical method. The need of a separation of PAHs and nitro-PAHs before the analysis was indicated by Schauer et al. (2004). PAHs and nitro-PAHs were separated before the analysis using a glass column with silica. PAHs were eluted with cyclohexane/ dichloromethane (in 1:1 ratio) fraction.

In turn, Bamford et al. (2003) used SPE and mixture of hexane and dichloromethane to separate PAHs and nitro-PAHs. This method was also used by Cochran et al. (2012). Nyiri et al. (2016) applied ultrasonic assisted extraction of PAHs and their oxy- and nitroderivatives with hexane as a solvent. Tang et al. (2016) and Fujiwara et al. (2014) applied dichloromethane as a solvent in the ultrasonic extraction of PAHs and nitro-PAHs. Wang et al. (2019) applied a novel method such as Matrix-Assisted Laser Desorption/Ionization Time-of-Flight Mass Spectrometry (MALDI-TOF-MS) with magnetic nanocomposites as matrix. This method has significant limitations in the analysis of small molecules (it is applied to analyze proteins and macromolecules), but an application of the right matrix (the authors used $\mathrm{Fe}_{3} \mathrm{O}_{4} / \mathrm{ZIF}-8$ magnetic nanocomposites) allowed to successful analysis of nitro-PAH. The proposed analytical procedures for nitro-PAHs are summarized in the Table 3. right after Section 3.1-3.3.

\subsection{O-PAHs}

In order to properly describe the analytical methods of O-PAHs, it is necessary to divide that group of compounds into hydroxy-PAHs and oxy-PAHs. Molecules belonging to the hydroxyl group require different preparation before the analysis. Cochran et al. (2012) indicate a necessity of sample derivatization prior to GC-MS analysis of hydroxy-PAHs. Hydroxy-PAHs require an inactivating hydroxyl group before the GC-MS analysis in contrast to PAHs, nitro-PAHs and oxy-PAHs, which can be analyzed without the derivatization. In this case, the mixture of bis(trimethylsilyl)trifluoroacetamide (BSTFA) and trimethylchlorosilane (TMCS) was used as a derivatization agent at $70{ }^{\circ} \mathrm{C}$ for $6 \mathrm{~h}$, and complete transformation of hydroxyl group was achieved. Similar procedure of OH-PAHs derivatization was proposed by Berger-Brito et al. (2018). Richter-Brockmann et al. (2019) proposed a transformation of $\mathrm{OH}-\mathrm{PAH}(3-\mathrm{OH}-\mathrm{BaP})$ into methyl ether using dimethyl sulfoxide, sodium hydroxide, and methyl iodide. After the reaction, the ether was extracted with cyclohexane using SPE. Then, they proposed GC-APLI-MS analysis. When the LC-MS method is applied, there is no need for derivatization of hydroxy-PAHs (Han et al. 2019). Barrado et al. (2012) applied low-temperature ultrasonication with methanol as an extraction solvent. The extraction procedure based on ethyl acetate was proposed by O'Connel et al. (2013); then, the GC and LC-MS techniques were used for quantification of 24 O-PAHs. Oxy-PAHs can be analyzed together with nitro-PAHs and PAHs without derivatization (Albinet et al. 2006). Han et al. (2019) proposed analysis of both nitro- and 
oxy-PAHs simultaneously. Also, Lammel et al. (2020) proposed a similar analytical procedure of both nitro- and oxy-PAHs, using GC-APCI-MS. Analytical investigation of oxyPAHs requires slightly different conditions of temperature than PAHs (Souza et al. 2014). Analytical procedures for O-PAH were collected and presented in Table 4. Please note that the table addresses not only PM-related air contaminations, but also reflects similar research devoted to soil, sediments, and urine analysis.

Sample preparation methods can be divided into two groups: adsorption techniques and extraction techniques using various extractants. The main analytical tools are GC and HPLC. The advantages and disadvantages of the presented techniques are difficult to assess due to the lack of the key value, which is LOD. For PAHs, the best method seems to be high volume sampler + ASE, for nitro-PAH, PSE with dichloromethane, and for O-PAH, ASE. HPLC is a better technique for hydroxy-PAH analysis as it does not require sample derivatization.

As it may be seen in Tables 2, 3 and 4, a variety of methods and their modifications have been proposed towards efficient analysis of PAHs, nitrated PAHs, oxygenated forms of PAHs (oxy-PAHs), and hydroxy-PAHs (OH-PAHs) in environmental samples. These tables summarize research on new sample treatment methods, sample analysis methods, and method performance for PAHs and their derivatives in various matrices. Not only were the samples extracted and purified by various methods, but the extracts were also analyzed by various techniques, such as gas chromatography, single and triple quadrupole mass spectrometry in electron ionization and negative ion chemical ionization with selective ion monitoring and reaction selective monitoring, as well as liquid chromatography and triple quadrupole mass spectrometry. Each group of analytes was treated by different analysis modes, such as GC-EI-SIM for PAH, GC-NICI-SRM for nitro-PAH, GC-EI-SRM for oxy$\mathrm{PAH}$, and LC-ESI-MS / MS for OH-PAH. The proposed instrumental techniques are very sensitive, ensuring detection of very low concentrations, even at the level of pg.

\section{Summary}

Analytical methods for basic PAHs are well developed, while in the case of derivatives (nitro-, oxy-, hydroxy-PAHs) there are still open questions. The main problem in the analysis of derivatives is their concentration in the air (much lower than basic compounds), their multiplicity (it is possible to form several derivatives from one basic compound), and the increased reactivity of some of them, which requires special treatment. Nevertheless, the analysis is similar for both PAHs and PAH derivatives, the main differences being in the sample preparation techniques.

PAHs can be successfully analyzed using GC/MS and HPLC (both in the reversed and normal phase system). The preparation of the environmental samples, usually taken on glass or quartz fiber filters, involves the extraction of compounds. To this goal, various techniques are used, such as Soxhlet extraction, and microwave and ultrasonic extraction.

In the case of nitro-derivatives of PAHs, it is possible to analyze them simultaneously with PAHs. These compounds can also be analyzed by GC and HPLC methods, but some research indicates that nitro-derivatives may be decomposed at higher temperatures. Therefore, HPLC is considered to be a better method for nitro-derivatives analysis in comparison with GC.

The hydroxy-PAHs analytics require the derivatization prior to the GC analysis. The $-\mathrm{OH}$ groups must be blocked before the GC analysis is started. Most often, this is done 


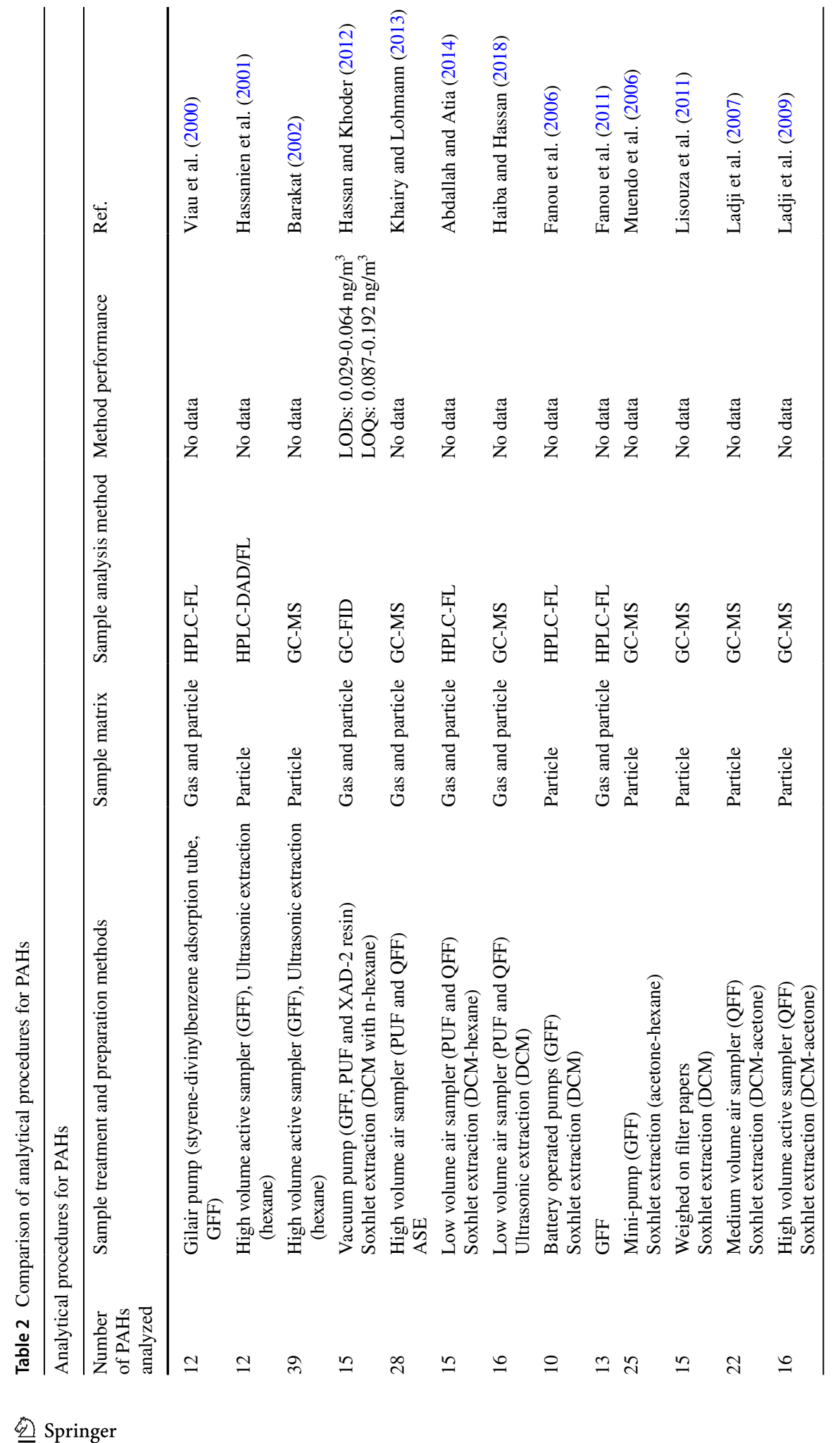




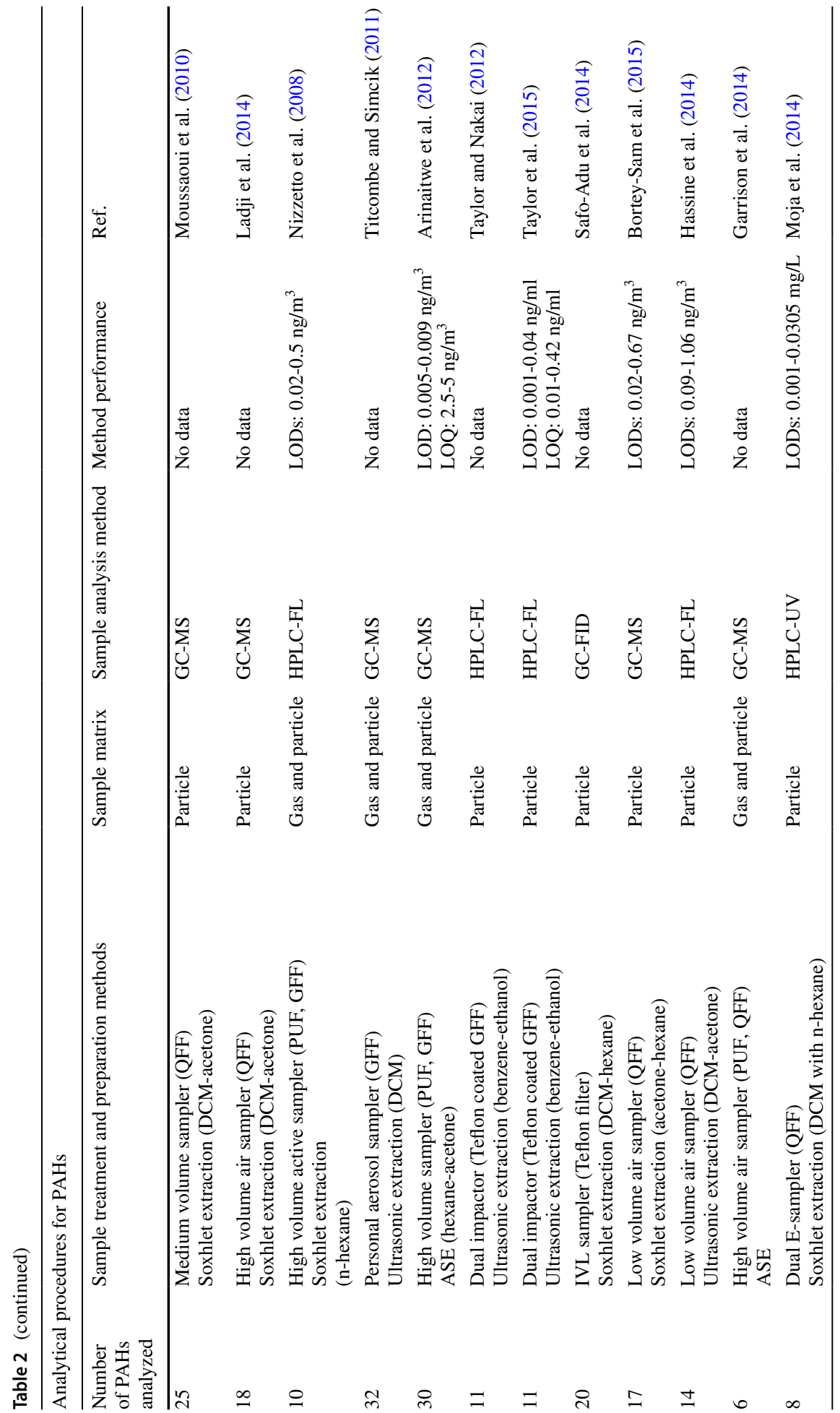




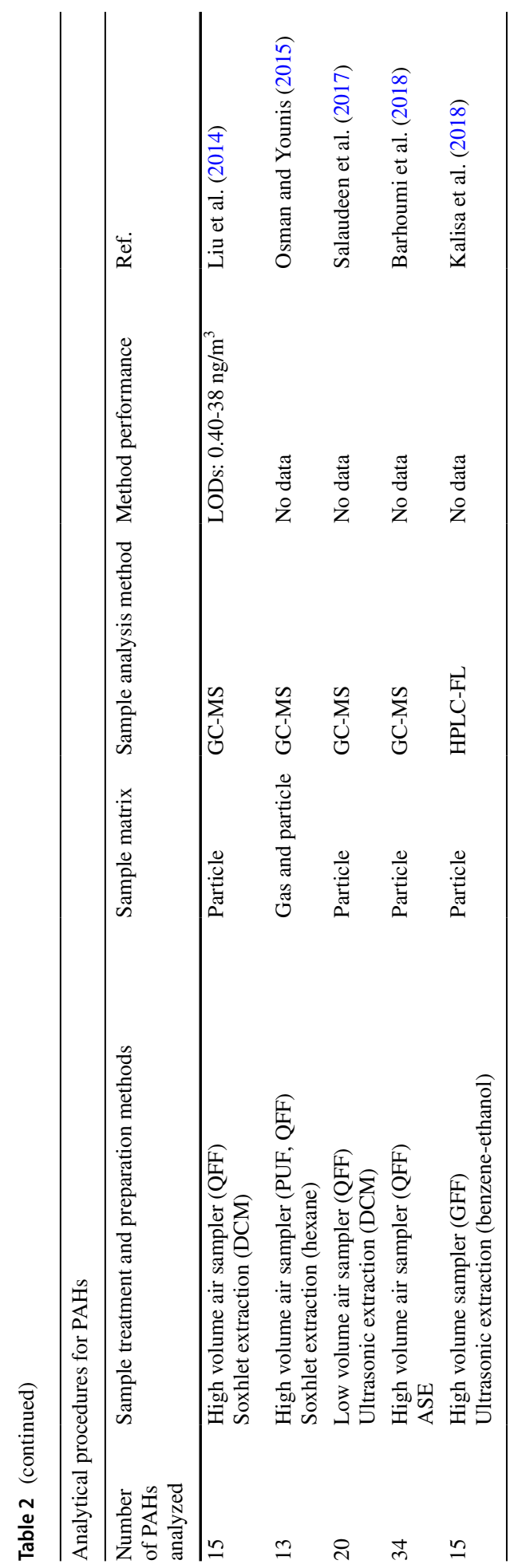




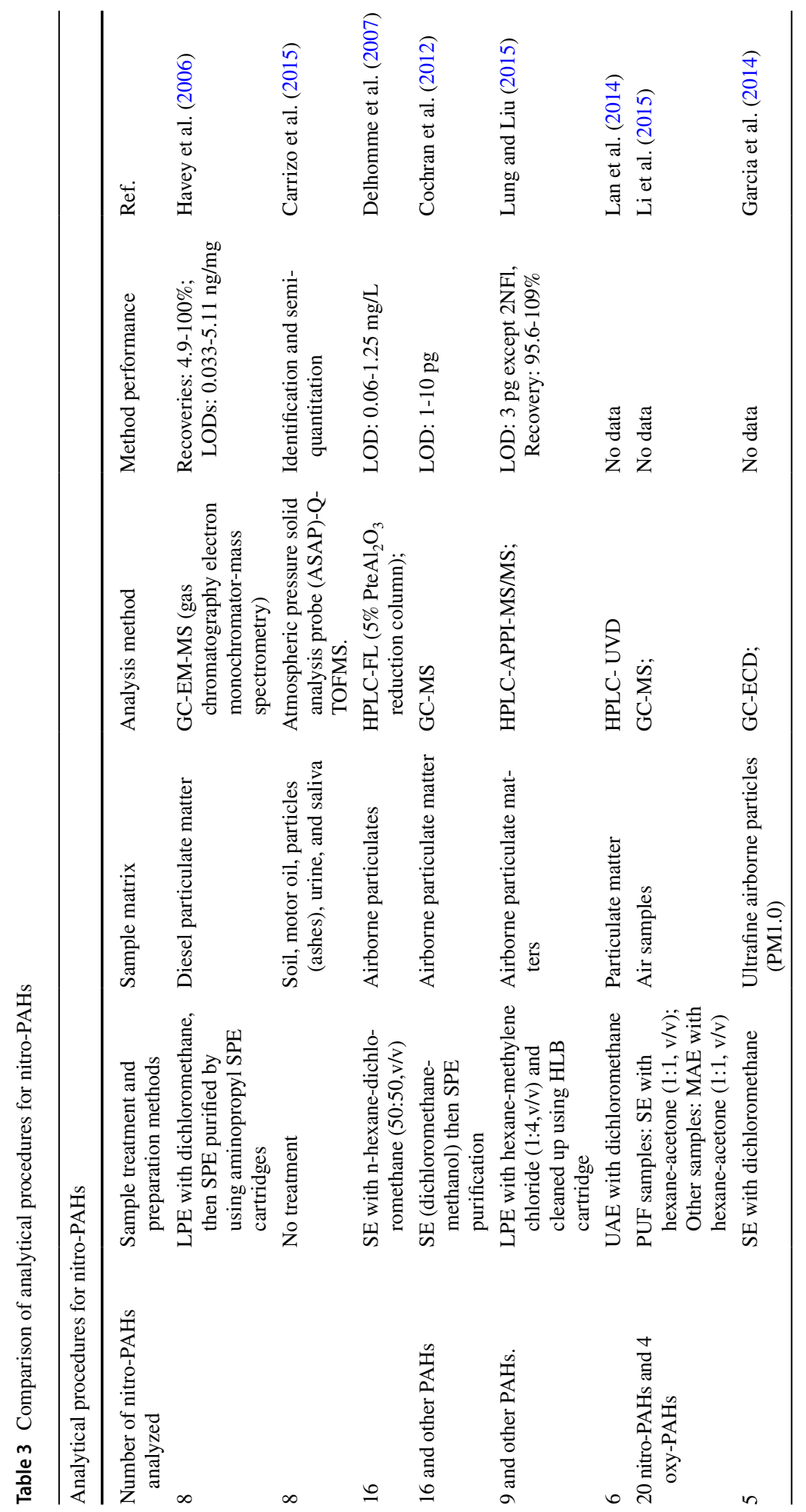




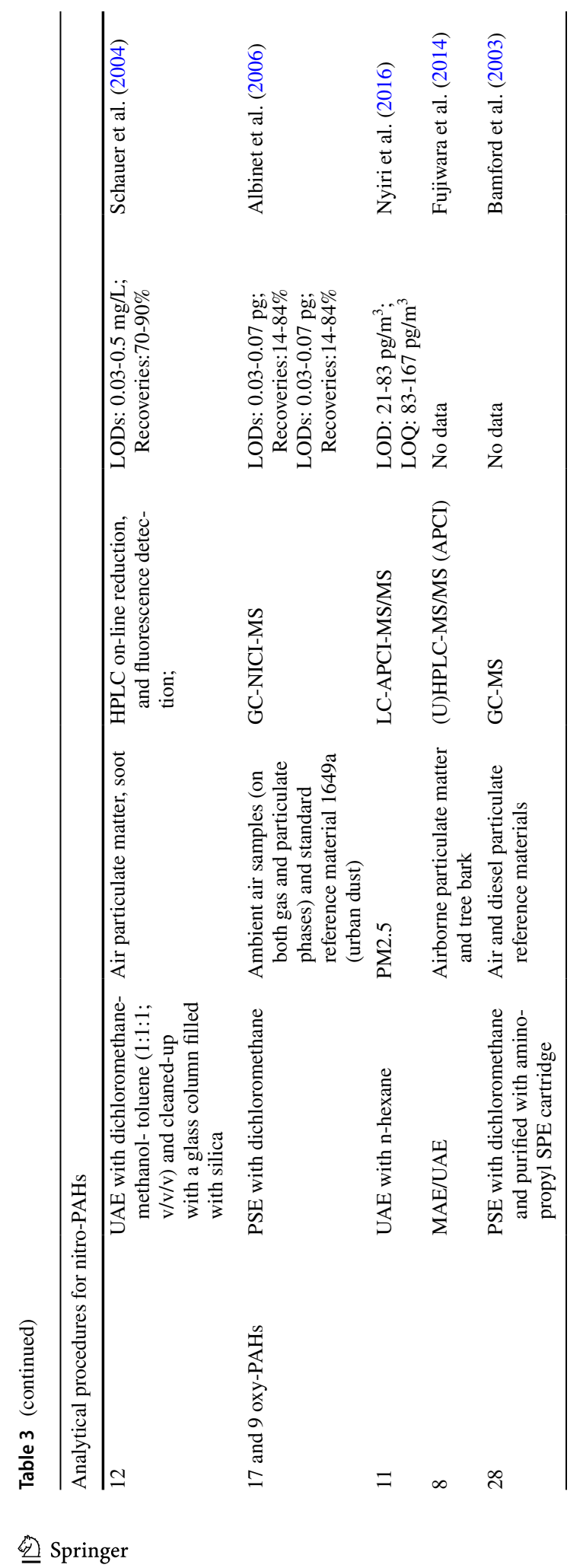




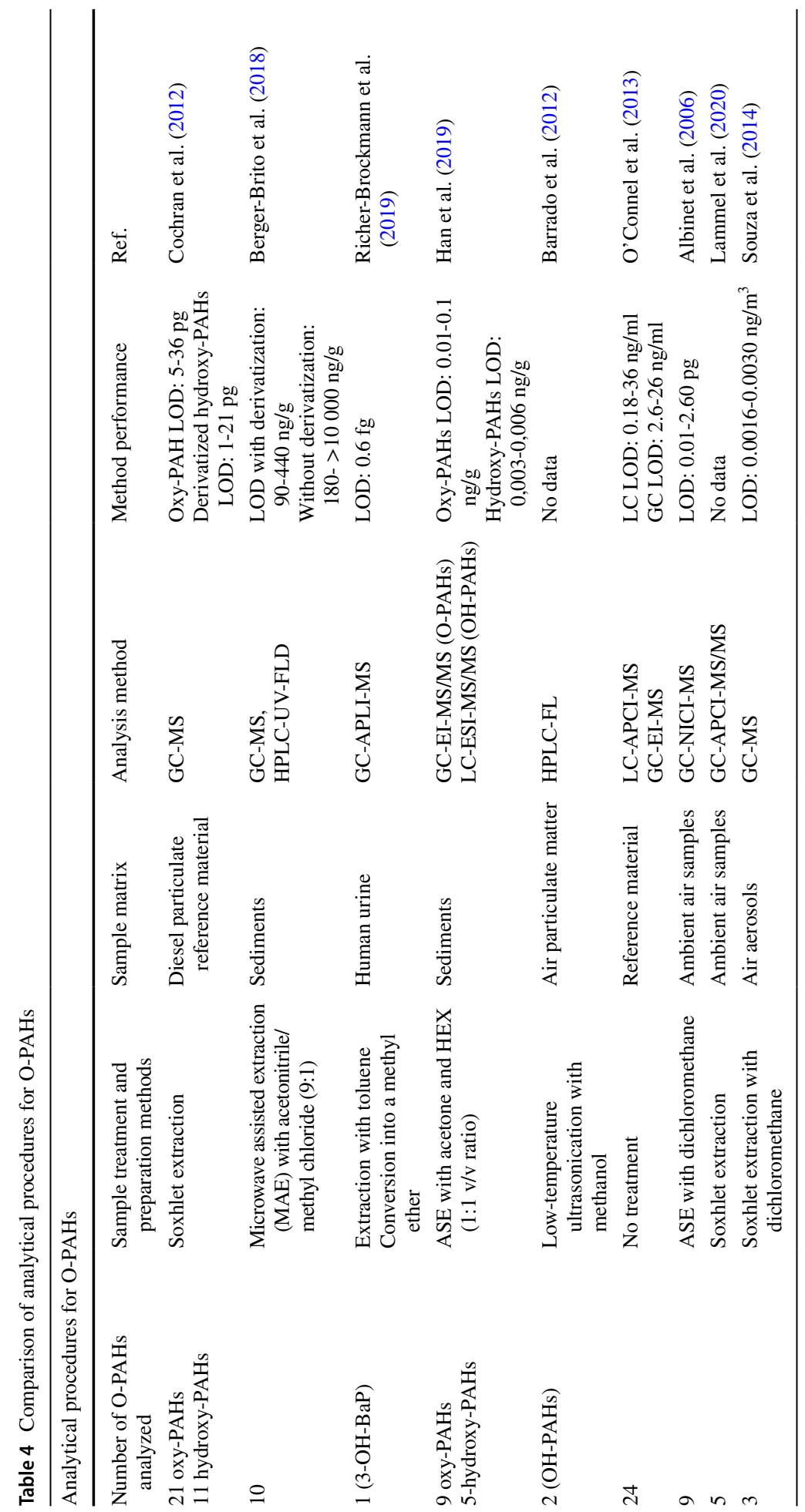


wwwwby wa reaction with a mixture of BSTFA and TMCS, or by a conversion of the hydroxyl groups to methyl ethers. When using liquid chromatography, there is no need to derivatize the samples. Even due to the increased polarity of these derivatives in relation to the parent compounds, it is not quite simple to separate these compounds; some research points to methanol as a good extractant for O-PAHs. During the analysis of O-PAHs, slightly different temperature conditions are required than in the analysis of PAHs. Therefore, it is difficult to determine all these compounds together; however, some research indicates the possibility of simultaneous determination of nitro- and oxy-derivatives.

It should be noticed that the PAH-derivatives analysis is a topic that recently drew much attention from scientists (Lawal 2017; Tran et al. 2020). The growing number of papers published on this subject shows that this topic is alive and still requires filling some knowledge gaps. Recently, the topic of researching indoor air quality, especially related to education, has emerged (Soggiu et al. 2020; Tripathy-Lang 2021; Reinmuth-Selzle et al. 2017). As regarding air pollution children are a very sensitive group, this topic should be further developed. At the same time, it is worth considering the sampling system, as well as several techniques for reducing the impact of the matrix. Moreover, the knowledge about PAH-derivatives formation mechanisms is significant and should be continuously developed. The interest in this topic is encouraged, along with the resulting increase in awareness not only of scientists, but also decision-makers.

\section{Conclusions}

The number of analytical methods concerning analysis of PAHs and its derivatives are impressive. However, one should remember that PAH determination methods are tools only for solving the main problem, i.e., an evaluation the health hazards associated with the presence of SPM in air. Thus, methods suitable for reaching this goal should be based on the application of GC or HPLC techniques equipped with relatively high accuracy, but using commonly available detectors. Due to the appearance of these compounds in the environment at very low concentrations, an analyte concentration step has to be applied prior to the analysis. These methods should be relatively simple but repeatable and assuring method LOD below the expected concentrations of PAHs and their derivatives in the environment.

According to the authors' opinion, there is need for two types of analytical methods: the standard method for environmental monitoring, and a second one suitable for detecting new potential PAH derivatives. The second group of mentioned methods should be based on HPLC or GC but equipped with very sensitive and reliable detectors such as Quadrupole - Time of Flight (Q-TOF). These techniques should be mainly aimed at qualitative analysis.

The main problem when using the GC technique is the need to derivatize OH-PAHs prior to analysis. In our opinion, there is a need to develop methods of simultaneous concentration and derivatization of the sample in order to avoid multi-stage processes. Moreover, a main drawback of several papers, found by authors in this review, i.e., the lack of information concerning LOD of these methods, makes applicability of these very limited.

Authors' Contributions All authors contributed to the study conception and design. Material preparation, data collection and analysis were performed by Michał Nowakowski, Iwona Rykowska and Przemysław Andrzejewski. The first draft of the manuscript was written by Michał Nowakowski and Robert Wolski. All 
authors commented on previous versions of the manuscript. All authors have read and approved the final manuscript.

Funding The work was supported by grant no. POWR.03.02.00-00-I020/17 co-financed by the European Union through the European Social Fund under the Operational Program Knowledge Education Development.

Data Availability Data sharing not applicable in this article as no datasets were generated during the current study.

\section{Declarations}

Competing Interest The authors declare that they have no known competing financial interest or personal relationships that could have appeared to influence the work reported in this paper.

Open Access This article is licensed under a Creative Commons Attribution 4.0 International License, which permits use, sharing, adaptation, distribution and reproduction in any medium or format, as long as you give appropriate credit to the original author(s) and the source, provide a link to the Creative Commons licence, and indicate if changes were made. The images or other third party material in this article are included in the article's Creative Commons licence, unless indicated otherwise in a credit line to the material. If material is not included in the article's Creative Commons licence and your intended use is not permitted by statutory regulation or exceeds the permitted use, you will need to obtain permission directly from the copyright holder. To view a copy of this licence, visit http://creativecommons.org/licenses/by/4.0/.

\section{References}

Abbas I, Badran G, Verdin A, Ledoux F, Roumie M, Courcot D, Garcon G (2018) Polycyclic aromatic hydrocarbons derivatives in airborne particulate matter: sources, analysis and toxicity. Environ Chem Lett 16:439-475

Abbasi S, Keshavarzi B (2019) Source identification of total petroleum hydrocarbons and polycyclic aromatic hydrocarbons in PM10 and street dust of a hot spot for petrochemical production: Asaluyeh Country, Iran. Sustain Cities Soc 45:214-230. https://doi.org/10.1016/j.scs.2018.11.015

Abdallah MAE, Atia NN (2014) Atmospheric concentrations, gaseous-particulate distribution, and carcinogenic potential of polycyclic aromatic hydrocarbons in Assiut, Egypt. Environ Sci Pollut Res - Int 21:8059-8069

Abdel-Shafy HI, Mansour MSM (2016) A review on polycyclic aromatic hydrocarbons: source, environmental impact, effect on human health and remediation. Egypt J Pet 25(1):107-123

Albinet A, Leos-Garziandia E, Budzinski H, Villenave E (2006) Simultaneous analysis of oxygenated and nitrated polycyclic aromatic hydrocarbons on standard reference material 1649a (urban dust) and on natural ambient air samples by gas chromatography-mass spectrometry with negative ion chemical ionisation. J Chromatogr A 1121:106-113

Arinaitwe K, Kiremire BT, Muir DC, Fellin P, Li H, Teixeira C, Mubiru DN (2012) Atmospheric concentrations of polycyclic aromatic hydrocarbons in the watershed of Lake Victoria, East Africa. Environ Sci Technol 46:11524-11531

Bamford HA, Bezabeh DZ, Schantz MM, Wise SA, Baker JE (2003) Determination and comparison of nitratedpolycyclic aromatic hydrocarbons measured in air and diesel particulate reference materials. Chemosphere 50:575-587

Bandowe BAM, Leimer S, Meusel H, Velescu A, Dassen S, Eisenhauer N, Hoffmann T, Oelmann Y, Wilcke W (2019) Plant diversity enhances the natural attenuation of polycyclic aromatic compounds (PAHs and oxygenated PAHs) in grassland soils. Soil Biol Biochem 129:60-70

Bandowe BAM, Meusel H, Huang R, Ho K, Cao J, Hoffman T, Wilcke W (2014) PM2.5-bound oxygenated PAHs, nitroPAHs and parent-PAHs from the atmosphere of a Chinese megacity: Seasonal variation, sources and cancer risk assessment. Sci Total Environ 473-474:77-87

Bandowe BAM, Meusel H (2017) Nitrated polycyclic aromatic hydrocarbons (nitro-PAHs) in the environment - A review. Sci Total Environ 581:237-257

Barakat AO (2002) PAHs and petroleum markers in the atmospheric environment of Alexandria City, Egypt. Water Air Soil Pollut 139:289-310 
Barhoumi B, Castro-Jiménez J, Guigue C, Goutx M, Sempere R, Derouiche A, Achour A, Touil S, Driss MR, Tedetti M (2018) Levels and risk assessment of hydrocarbons and organochlorines in aerosols from a North African coastal city (Bizerte, Tunisia). Environ Pollut 240:422-431

Barrado AI, Garcia S, Barrado E, Perez RM (2012) PM2.5bound PAHs and hydroxy-PAHs in atmospheric aerosol samples: Correlations with season and with physical and chemical factors. Atmos Environ 49:224-232

Barrado AI, Garcia S, Castrillejo Y, Barrado E (2013) Exploratory data analysis of PAH, nitro-PAH and hydroxyl-PAH concentrations in atmospheric PM10-bound aerosol particles. Correlations with physical and chemical factors. Atmos Environ 67:385-393

Berger-Brito I, Machour N, Morin C, Portet-Koltalo F (2018) Experimental Designs for Optimizin MultiResidual Microwave-assisted Extraction and Chromatographic Analysis of Oxygenated (Hydroxylated, Quinones) Metabolites of PAHs in Sediments. Chromatographia 81:1401-1412

Boac JM, Maghirang RG, Casada ME, Wilson JD, Jung YS (2009) Size distribution and rate of dust generated during grain elevator handling. Appl Eng Agric 25:533-541

Boldo E, Medina S, Le Terte A, Hurley F, Muecke HG, Ballester F, Aguilera I, Eilstein D (2006) Aphesis: Health Impact Assessment of Long-term Exposure to PM2.5 in 23 European Cities. Eur J Epidemiol 21:449-458

Bortey-Sam N, Ikenaka Y, Akoto O, Nakayama SM, Yohannes YB, Baidoo E, Mizukawa H, Ishizuka M (2015) Levels, potential sources and human health risk of polycyclic aromatic hydrocarbons (PAHs) in particulate matter (PM 10) in Kumasi, Ghana. Environ Sci Pollut Res - Int 22:9658-9667

Brorström-Lunden E, Remberger M, Kaj L, Hansson K, Palm Cousins A, Andersson H, Haglund P, Ghebremeskel M, Schlabach M (2008) Results Fron the Swedish Nationa Screening Programme 2008: Screening of Unintentionally Produced Organic Contaminants, Swedish Environmental Research Institute (IVL) report B1944

Brown JS, Gordon T, Price O, Asgharian B (2013) Thoracic and respirable particle definitions for human health risk assessment. Part Fibre Toxicol 10(1):12

Carrizo D, Domeno C, Nerin I (2015) Atmospheric pressure solid analysis probe coupled to quadrupoletime of flight mass spectrometry as a tool for screening and semi-quantitative approach of polycyclic aromatic hydrocarbons, nitro-polycyclic aromatic hydrocarbons and oxo-polycyclic aromatic hydrocarbons in complex matrices. Talanta 131:175-184

Cochran RE, Dongari N, Jeong H, Beranek J, Haddadi S, Shipp J, Kubatova A (2012) Determination of polycyclic aromatic hydrocarbons and their oxy-, nitro-, and hydroxyoxidation products. Anal Chim Acta 740:93-103

Collins J, Brown J, Alexeeff G, Salmon A (1998) Potency equivalency factors for some polycyclic aromatic hydrocarbons and polycyclic aromatic hydrocarbons derivatives. Regul Toxicol Pharmacol 28:45-54

Cordeiro DS, Corio P (2009) Electrochemical and photocatalytic reactions of polycyclic aromatic hydrocarbons investigated by raman spectroscopy. J Braz Chem Soc 20. https://doi.org/10.1590/S010350532009000100014

Crimmins BS, Baker JE (2006) Improved GC/MS methods for measuring hourly PAH and nitro-PAH concentrations in urban particulate matter. Atmos Environ 40:6764-6779

de Oliveira Galvao MF, de Oliveira Alves N, Ferreira PA, Caumo S, de Castro Vasconcellos P, Artaxo P, de Souza Hancon S, Roubicek DA, de Medeiros SR (2018) Biomass burning particles in the Brazilian Amazon region: Mutagenic effects of nitro and oxy-PAHs and assessment of health risks. Environ Pollut 233:960-970. https://doi.org/10.1016/j.envpol.2017.09.068

Delhomme O, Herckes P, Millet M (2007) Determination of nitro-polycyclic aromatic hydrocarbons in atmospheric aerosols using HPLC fluorescence with a post-column derivatisation technique. Anal Bioanal Chem 389(6):1953-1959

Deng WJ, Louie PKK, Liu WK, Bi XH, Fu JM, Wong MH (2006) Atmospheric levels and cytotoxicity of PAHs and heavy metals in TSP and PM2.5 at an electronic waste recycling site in southeast China. Atmos Environ 40:6945-6955

dos Santos RR, Leal LDV, Cardeal ZL, Menezes HC (2019) Determination of polycyclic aromatic hydrocarbons and their nitrated and oxygenated derivatives in coffee brews using an efficient cold fibersolid phase microextraction and gas chromatogramphy mass spectrometry method. J Chromatogr A 1584:64-71

Drotikova T, Ali AM, Halse AK, Reinardy HC, Kallenborn R (2020) Polycyclic aromatic hydrocarbons (PAHs), oxy-, and nitro-PAHs in ambient air of Arctic town Longyearbyen Svalbard. Atmos Chem Phys 20:9997-10014

Fanou LA, Avogbe PH, Fayomi B, Keith G, Hountondji C, Creppy EE, Autrup H, Rihn BH, Sanni A (2011) DNA-adducts in subjects exposed to urban air pollution by benzene and polycyclic aromatic hydrocarbons (PAHs) in Cotonou, Benin. Environ Toxicol 26:93-102 
Fanou LA, Mobio TA, Creppy EE, Fayomi B, Fustoni S, Møller P, Kyrtopoulos S, Georgiades P, Loft S, Sanni A (2006) Survey of air pollution in Cotonou, Benin-air monitoring and biomarkers. Sci Total Environ 358:85-96

Fujiwara F, Guinez M, Cerutti S, Smichowski P (2014) UHPLC-(+)APCI-MS/MS determination of oxygenated and nitrated polycyclic aromatic hydrocarbons in airborne particulate matter and tree barks collected in Buenos Aires city. Microchem J 116:118-124

Gao Y, Yang L, Chen J, Li Y, Jiang P, Zhang J, Wang W (2018) Nitro and oxy-PAHs bounded in PM 2.5 and PM 1.0 under different weather conditions at Mount Tai in Eastern China: Sources, long-distance transport, and cancer risk assessment. Sci Total Environ 622-623:1400-1407

Garcia KO, Teixeira EC, Agudelo-Castaneda DM (2014) Assessment of nitropolycyclic aromatic hydrocarbons in PM1 near an area of heavy-duty traffic. Sci Total Environ 479e480:57-65

Garcia-Alonso S, Barrado-Olmedo AI, Perez-Pastor RM (2012) An Analytical Method to Determine Selected Nitro-PAHs in Soil Samples by HPLC With Fluorescence Detection. Polycycl Aromat Compd 32(5):669-682

Garrison VH, Majewski MS, Foreman WT, Genualdi SA, Mohammed A, Simonich SM (2014) Organic contaminants in Saharan dust air masses in West Africa, Cape Verde and the eastern Caribbean, Sci. Total Environ 468:530-Persistent

Haiba N, Hassan I (2018) Monitoring and assessment of polycyclic aromatic hydrocarbons (PAHs) in the atmosphere of Alexandria City. Egypt, Polycycl Aromat Compd 38:219-230

Han M, Kong J, Yuan J, He H, Hu J, Yang S, Li S, Zhang L, Sun C (2019) Method development for simultaneous analyses of polycyclic aromatic hydrocarbons and their nitro-, oxy-, hydroxy- derivatives in sediments. Talanta 205:120-128

Hassan SK, Khoder M (2012) Gas-particle concentration, distribution, and health risk assessment of polycyclic aromatic hydrocarbons at a traffic area of Giza, Egypt. Environ Monit Assess 184:3593-3612

Hassanien MA, Rieuwerts J, Shakour A, Bittó A (2001) Seasonal and annual variations in air concentrations of $\mathrm{Pb}, \mathrm{Cd}$ and PAHs in Cairo, Egypt. Int J Environ Health Res 11:13-27

Hassine SB, Hammami B, Ameur WB, El Megdiche Y, Barhoumi B, Driss M (2014) Particulate polycyclic aromatic hydrocarbons (PAH) in the atmosphere of Bizerte City, Tunisia. Bull Environ Contam Toxicol 93:375-382

Havey CD, McCormick RL, Hayes RR (2006) Analysis of nitro-polycyclic aromatic hydrocarbons in conventional diesel and Fischer-Tropsch diesel fuel emissions using electron monochromator-mass spectrometry. Anal Chem 78(14):4894-4900

Hayakawa K (2018) Chemistry of polycyclic aromatic hydrocarbons (PAHs), nitropolycyclic aromatic hydrocarbons (NPAHs) and oxidative derivatives of PAHs. In: Hayakawa K (ed) Polycyclic Aromatic Hydrocarbons: Environmental Behavior and Toxicity in East Asia, ISBN: 978-981-10-6774-7, pp 3-10

Idowu O, Semple KT, Ramadass K, O'Connor W, Hansbro P, Thavaman P (2019) Analysis of polycyclic aromatic hydrocarbons (PAHs) and their polar derivatives in soils of an industrial heritage city of Australia. Sci Total Environ 699:134303

International Agency for Research on Cancer (2016) IARC monographs on the evaluation of carcinogenic risks to humans: vol. 109, Outdoor Air Pollution. IARC, Lyon

Jakovljević I, Pehnec G, Vadić V, Ćaćkowić M, Tomasić V, Doko Jelinić J (2018) Polycyclic aromatic hydrocarbons in PM10, PM2.5 and PM1 particle fractions in an urban area. Air Qual Atmos Health 11:843-854

Jiping M, Hou L, Wu G, Wang L, Wang X, Chen L (2020) Multi-walled carbon nanotubes for magnetic solid-phase extraction of six heterocyclic pesticides in environmental water samples followed by HPLC-DAD determination. Materials 13:5729

Kalisa E, Nagato EG, Bizuru E, Lee KC, Tang N, Pointing SB, Hayakawa K, Archer SD, Lacap-Bugler DC (2018) Characterization and risk assessment of atmospheric PM2. 5 and PM10 particulate-bound PAHs and NPAHs in Rwanda, Central-East Africa. Environ Sci Technol 52:12179-12187

Kaneta T, Alahmad W, Varanusupakul P (2018) Microfluid paper-based analytical devices with instrumentfree detection and miniaturized portable detectors. Appl Spectrosc Rev 54(2):1-25

Keith LH (2014) The source of U.S. EPA's sixteen PAH priority pollutants. Polycycl Aromat Compd 35:2-4

Khairy MA, Lohmann R (2013) Source apportionment and risk assessment of polycyclic aromatic hydrocarbons in the atmospheric environment of Alexandria, Egypt. Chemosphere 91:895-903

Kic P (2018) Influence of housing technology on dust level in cowsheds, In: Proceedings of 17th International Scientific Conference 'Engineering for rural development", Jelgava, Latvia, pp 24-27

Kim KH, Jahan SA, Kabir E, Brown RJC (2013) A review of airborne polycyclic aromatic hydrocarbons (PAHs) and their human health effects. Environ Int 60:71-80 
Kitanovski Z, Shahpoury P, Samara C, Voliotis A, Lammel G (2020) Composition and mass size distribution of nitrated and oxygenated aromatic compounds in ambient particulate matter from southern and central Europe - implications for the origin. Atmos Chem Phys 20:2471-2487

Kubiak MS (2013) Polycyclic aromatic hydrocarbons (PAHs) - occurrence in the environment and food. Hyg Epidemiol Prob 94(1) (in polish)

Kurnia A, Lim LW, Takeuchi T (2018) Determination of Polycyclic Aromatic Hydrocarbons (PAHs) using environmental friendly liquid chromatography. Makara J Sci 22(1):42-51

Ladji R, Yassaa N, Balducci C, Cecinato A (2014) Particle size distribution of n-alkanes and polycyclic aromatic hydrocarbons (PAHS) in urban and industrial aerosol of Algiers, Algeria. Environ Sci Pollut Res - Int 21:1819-1832

Ladji R, Yassaa N, Balducci C, Cecinato A, Meklati BY (2009) Distribution of the solvent-extractable organic compounds in fine (PM1) and coarse (PM1-10) particles in urban, industrial and forest atmospheres of Northern Algeria. Sci Total Environ 408:415-424

Ladji R, Yassaa N, Cecinato A, Meklati BY (2007) Seasonal variation of particulate organic compounds in atmospheric PM10 in the biggest municipal waste landfill of Algeria. Atmos Res 86:249-260

Lammel G (2015) Polycyclic aromatic compounds in atmosphere - a review identifying research needs. Polycyclic Aromatic Hydrocarbons 35:316-329

Lammel G, Kitanovski Z, Kukucka P, Novak J, Arangio A, Codling G, Filippi A, Hovorka J, Kuta J, Leoni C, Pribylowa P, Prokes R, Sanka O, Shahpoury P, Tong H, Wietzoreck M (2020) Oxygenated and nitrated polycyclic aromatic hydrocarbons in ambient air - Levels, phase partioning, mass size distributions, and inhalation bioaccessibility. Environ Sci Technol 52(5):2615-2625

Lan SH, Lan HX, Yang D (2014) Study of nitro-polycyclic aromatic hydrocarbons in particulate matter in Dongguan. Environ Sci Pollut Res Int 21(12):7390-7399

Lawal AT (2017) Polycyclic aromatic hydrocarbon. A review. Cogent Environ Sci 3:1339841

Li W, Wang C, Shen H (2015) Concentrations and origins of nitro-polycyclic aromatic hydrocarbons and oxy-polycyclic aromatic hydrocarbons in ambient air in urban and rural areas in northern China. Environ Pollut 197:156-164

Lisouza FA, Owuor OP, Lalah JO (2011) Variation in indoor levels of polycyclic aromatic hydrocarbons from burning various biomass types in the traditional grass-roofed households, in Western Kenya. Environ Pollut 159:1810-1815

Lisowski P, Zarzycki PK (2013) Microfluid Paper-based Analytical Devices ( $\mu$ PADs) and Micro Total Analysis Systems ( $\mu$ TAS): Development, applications and future trends. Chromatographia 76(19):1201-1214

Liu J, Xu Y, Li J, Liu D, Tian C, Chaemfa C, Zhang G (2014) The distribution and origin of PAHs over the Asian marginal seas, the Indian, and the Pacific Oceans: implications for outflows from Asia and Africa. J Geophys Res Atmos 119:1949-1961

Lu JW, Flores JM, Lavi A, Abo-Riziq A, Rudich Y (2011) Changes in the optical properties of benzo[a] pyrene-coated aerosols upon heterogeneous reactions with NO2 and NO3. Phys Chem Chem Phys 14. https://doi.org/10.1039/C0CP02114H

Lung SC, Liu C (2015) Fast analysis of 29 polycyclic aromatic hydrocarbons (PAHs) and nitro-PAHs with ultra-high performance liquid chromatography atmospheric pressure photoionization-tandem mass spectrometry. Sci Rep 5(1):12992

Manousi N, Zachariadis GA (2020) Recent advances in the extraction of polycyclic aromatic hydrocarbons from environmental samples. Molecules 25:2182

Mirivel G, Riffault V, Galloo J-C (2010) Simultaneous determination by ultra-performance liquid chromatographyatmospheric pressure chemical ionization time-of-flight mass spectrometry of nitrated and oxygenated PAHs found in air and soot particles. Anal Bioanal Chem 397(1):243-256

Moja SJ, Mtunzi F, Mnisi JS (2014) Determination of some polycyclic aromatic hydrocarbons (PAHs) associated with airborne particulate matter by high performance liquid chromatography (HPLC) method, Afr. J Environ Sci Technol 8:210-218

Moorthy B, Chu C, Carlin DJ (2015) Polycyclic aromatic hydrocarbon: from metabolism to lung cancer. Toxicol Sci 145(1):5-15

Moussaoui Y, Balducci C, Cecinato A, Meklati BY (2010) Chemical composition of extractable organic matter of airborne particles in urban and rural atmospheres of Northern Algeria. Fresenius Environ Bull 19:2497-2508

Mueller A, Ulrich N, Hollmann J, Zapata Sanchez CE, Rolle-Kampczyk UE, von Bergen M (2019) Characterization of a multianalyte GC-MS/MS procedure for detecting and quantifying polycyclic aromatic hydrocarbons (PAHs) and PAH derivatives from air particulate matter for an improved risk assessment. Environ Pollut 255(2):112967 
Muendo M, Hanai Y, Kameda Y, Masunaga S (2006) Polycyclic aromatic hydrocarbons in urban air: concentration levels, patterns, and source analysis in Nairobi, Kenya. Environ Forensics 7:147-157

Mulder M, Dumanoglu Y, Efstathiou C, Kukucka P, Matejovicowa J, Maurer C, Pribylowa P, Prokes R, Sofuoglu A, Sofuoglu S, Wilson J, Zetzsch C, Wotawa G, Lammel G (2019) Fast formation of NitroPAHs in the marine atmosphere constrained in a regional-scale langrangian field experiment. Environ Sci Technol 53:8914-8924

Munyeza CF, Rohwer ER, Forbes PBC (2019) A review of monitoring of airborne polycyclic aromatic hydrocarbonsL An African perspective. Anal Chem 24. https://doi.org/10.1016/j.teac.2019.e00070

Nascimento MM, Da Rocha GO, Bittencourt de Andrade J (2019) Simple and effective dispersive microsolid phase extraction procedure for simultaneous determination of polycyclic aromatic compounds in fresh and marine water. Talanta 204. https://doi.org/10.1016/j.talanta.2019.06.06

Nizzetto L, Lohmann R, Gioia R, Jahnke A, Temme C, Dachs J, Herckes P, Guardo AD, Jones KC (2008) PAHs in air and seawater along a North-South Atlantic transect: trends, processes and possible sources. Environ Sci Technol 42:1580-1585

Nyiri Z, Novak M, Bodai Z, Szabó BS, Eke Z, Zaray G, Szigeti T (2016) Determination of particulate phase polycyclic aromatic hydrocarbons and their nitrateg and oxygenated derivatives using gas chromatographymass spectrometry and liquid chromatography-tandem mass spectrometry. J Chromatogr A 1472:88-98

O'Connell SG, Haigh T, Wilson G, Anderson KA (2013) An analytical investigation of 24 oxygenatedPAHs (OPAHs) using liquid and gas chromatography-mass spectrometry. Anal Bioanal Chem 405(27):8885-8896

OEHHA (2005) Adopted air toxics "hot spots" program risk assessment guidelines Part II 2005: Technical support document for describing available cancer potency factors, California Office of Environmental Health Hazard Assessment, Sacramento, CA, https://oehha.ca.gov/media/downloads/crnr/ may2005hotspots.pdf

Oleagoitia MBZ, Manterola AL, Maruolagoitia JI, López de Dicastillo MDM, Alvarez J, Barandiaran MA, Loibide AI, Santa-Maria L (2019) Polycyclic aromatic hydrocarbons (PAHs) in air associated with particles PM2.5 in the Basque Country (Spain). Air Qual Atmos Health 12:107-114

Oliveira M, Slezakova K, Delerue-Matos C, Carmo Pereira M, Morias S (2019) Children environmental exposure to particulate matter and polycyclic aromatic hydrocarbons and biomonitoring in school environments: A review on indoor and outdoor exposure levels, major sources and health impact. Environ Int 124:180-204

Osman MM, Younis YM (2015) Estimation of polycyclic aromatic hydrocarbons (PAHs) pollutants in the ambient air of Khartoum City, Sudan (Part III). Int J Res Pharm Chem 5:327-333

Ozaki N, Kindaichi T, Ohashi A (2020) PAHs emission source analysis for air and water environments by isomer ratios - Comparision by modified Cohen's d. Sci Total Environ 715:136831

Pham CT, Boongla Y, Nghiem TD, Le HT, Tang N, Toriba A, Hayakawa K (2019) Emission characteristic of polycyclic aromatic hydrocarbons and nitro-polycyclic aromatic hydrocarbons from open burning of Rice Straw in the North of Vietnam. Int J Environ Res Public Health 16(13):2343

Ravindra K, Mittal AK, van Grieken R (2001) Health risk assessment of urban suspended particulate matter with special reference to polycyclic aromatic hydrocarbons: a review. Rev Environ Health 16:169-189

Reinmuth-Selzle K, Kampf CJ, Lucas K, Lang-Yona N, Froehlich-Nowoisky J, Shiraiwa M, Lakey PSJ, Lai S, Liu F, Kunert AT, Ziegler K, Shen F, Sgarbanti R, Weber B, Bellinghausen I, Saloga J, Weller MG, Dusch A, Schuppan D, Poeschl U (2017) Air pollution and climate change effects on allergies in the anthropocene: abundance, interaction and modification of allergens and adjuvants. Environ Sci Technol 51(8):4119-4141

Reizer M (2016) What is particulate matter? Fine dust in the atmosphere - a compendium of knowledge about air pollution with particulate matter in Poland, Environmental monitoring library (in polish)

Richer-Brockmann S, Dettbarn G, Jessel S, John A, Seidel A, Achten C (2019) Ultra-high sensitive analysis of 3-hydroxybenzo[a]pyrene in hyman urine using GC-APLI-MS. J Chromatogr B 1118-1119:187-193

Ringuet J, Albinet A, Leoz-Garziandia E, Budzinski H, Vilenave E (2012) Reactivity of polycyclic aromatic compounds (PAHs, NPAHs and OPAHs) adsorbed on natural aerosol particles exposed to atmospheric oxidants. Atmos Environ 61:15-22

Rostkowski P, Horwood J, Shears JA, Lange A, Oladapo FO, Besselink HT, Tyler CR, Hill EM (2011) Bioassaydirected identification of novel antiandrogenic compounds in bile of fish exposed to wastewater effluents. Environ Sci Technol 45(24):10660-7

Safo-Adu G, Ofosu FG, Carboo D, Serfor-Armah Y (2014) Health risk assessment of exposure to particulate polycyclic aromatic hydrocarbons at a tollbooth on a major highway. Am J Sci Ind Res 5:110-119

Salaudeen I, Sonibare O, Sojinu S, Ekundayo O (2017) Polycyclic aromatic hydrocarbons in air from industrial areas in Lagos and Ogun states, Nigeria. Pollution 3:561-573 
Saldarriga-Norena H, Lopez-Marquez R, Murillo-Tovar MA, Arias-Montoya MI, Guerrero-Alvarez JA, Vergara-Sanchez J (2018) Recent advances for polycyclic aromatic analysis in airborne particulate matter. In: Ince M (ed) Hydrocarbon pollution and its effect on the environment. ISBN: 978-178984-421-4, pp 53-70

Sapota A (2002) Polycyclic aromatic hydrocarbons (tar substances soluble in cyclohexane). Documentation of the proposed occupational exposure limit values. Bases and Methods of Work Environmental Assessment, R 18 2(32):179-208

Schauer C, Niessner R, Poeschl U (2004) Analysis of nitrated polycyclic aromatic hydrocarbons by liquid chromatography with fluorescence and mass spectrometry detection: air particulate matter, soot, and reaction product studies. Anal Bioanal Chem 378:725-736

Schwartz Cowan R (1997) A Social History of American Technology, Oxford University Press, ISBN: 9780195046052. https://EconPapers.repec.org/RePEc:oxp:obooks:9780195046052

Singh R, Yadav A, Chopra A, Christopher J, Kapur GS (2019) Comparison of five different HPLC columns with different particle sizes, lengths and make for optimization of seven polycyclic aromatic hydrocarbons (PAH) analysis. SN Appl Sci 1:313

Souza KF, Carvalho LRF, Allen AG, Cardoso AA (2014) Diurnal and nocturnal measurements of PAH, nitro-PAH, and oxy-PAH compounds in atmospheric particulate matter of a sugar cane burning region. Atmos Environ 83:193-201

Soggiu ME, Inglessis M, Gagliardi RV, Settimo G, Marsili G, Notardonato I, Avino P (2020) PM10 and PM2.5 Qualitative Source Apportionment Using Selective Wind Direction Sampling in a PortIndustrial Area in Civitavecchia, Italy. Atmsphere 11(1):94. https://doi.org/10.3390/atmos11010094

Srogi K (2007) Monitoring of environmental exposure to polycyclic aromatic hydrocarbons: a review. Environ Chem Lett 5:169-195

Sun C, Qu L, Qu L, Sun R, Li Y (2020) Advances in analysis of nitrated polycyclic aromatic hydrocarbons in various matrices. TRAC Trends Anal Chem 127:115878

Szulejko JE, Ki-Hyun K, Brown RJC, Min-Suk B (2014) Review of progress in solvent-extraction techniques for the determination of polyaromatic hydrocarbons as airborne pollutants. TRAC Trends Anal Chem 41:40-48

Tang Y, Imasaka T, Yamamoto S, Imasaka T (2016) Determination of polycyclic aromatic hydrocarbons and their nitro-, aminoderivatives absorbed on particulate matter 2.5 by multiphoton ionization mass spectrometry using far-, deep-, and nearultraviolet femtosecond lasers. Chemosphere 152:252-258

Taylor E, Wirmvem M, Sawyerr V, Nakai S (2015) Characterization and determination of PM2. 5 Bound polycyclic aromatic hydrocarbons (PAHS) in indoor and outdoor air in Western Sierra Leone. J Environ Anal Toxicol 5:2161-0525

Taylor ET, Nakai S (2012) Monitoring the levels of toxic air pollutants in the ambient air of Freetown, Sierra Leone. Afr J Environ Sci Technol 6:283-292

Titcombe ME, Simcik M (2011) Personal and indoor exposure to PM 2.5 and polycyclic aromatic hydrocarbons in the southern highlands of Tanzania: a pilot-scale study. Environ Monit Assess 180:461-476

Tran VV, Park D, Lee YC (2020) Indoor air pollution, related human diseases and recent trends in the control and improvement of indoor air quality. Int J Environ Res Public Health 17(8):2927

Tripathy-Lang A (2021) How can wristbands monitor pollution, PAHs and prenatal care? Eos 102. https://doi.org/10.1029/2021EO162660

Umbuzeiro GA, Franco A, Martins MH, Kummrow F, Carvalho L, Schmeiser HH, Leykauf J, Stiborova M, Claxton LD (2008) Mutagenicity and DNA adduct formation of PAH, nitro-PAH and oxy-PAH fractions of atmospheric particulate matter from Sao Paulo, Brazil. Mutat Res 652:72-80

USEPA, Office of Solid Waste (2008) Polycyclic aromatic hydrocarbons (PAHs), https://archive.epa.gov/ epawaste/hazard/wastemin/web/pdf/pahs.pdf. Accessed 1 Nov 2015

Viau C, Hakizimana H, Bouchard M (2000) Indoor exposure to polycyclic aromatic hydrocarbons and carbon monoxide in traditional houses in Burundi. Int Arch Occup Environ Health 73:331-338

Vione D, Barra S, De Gennaro G, De Rienzo M, Gilardoni S, Perrone MG, Pozzoli L (2004) Polycyclic aromatic hydrocarbons in the atmosphere: monitoring, sources, sinks and fate. Ann Chim 94:257-268

Walgraeve C, Demeestere K, Dewulf J, Zimmermann R, van Langenhove H (2010) Oxygenated polycyclic aromatic hydrocarbons in atmospheric particulate matter: Molecular characterization and occurrence. Atmos Environ 44:1831e1846

Wang H, Wang X, Bian W, Sun T, Cai Z, Wei J (2019) Analysis of nitropolycyclic aromatic hydrocarbons in fine particulate matter by Matrix-Assisted Laser Desorption/Ionization Time-of-Flight Mass Spectrometry Using $\mathrm{Fe}_{3} \mathrm{O}_{4} / \mathrm{ZIF}-8$ magnetic nanocomposites as matrix. J Appl Spectrosc 86(1):89-95

Wilcke W, Bandowe BAM, Gomez Lueso M, Ruppenthal M, del Valle H, Oelmann Y (2014) Polycyclic aromatic hydrocarbons (PAHs) and their polar derivatives (oxygenated PAHs, azaarenes) in soils along a climosequence in Argentina. Sci Total Environ 473-474:317-325 
Wilson WB, Hayes HV, Sander LC, Campiglia AD, Wise SA (2017) Normal-phase liquid chromatography retention behavior of polycyclic aromatic hydrocarbon and their methyl-substituted derivatives on an aminopropyl stationary phase. Anal Bioanal Chem 409:5291-5305

Zaciera M (2007) Research on the determination of nitro derivatives of polycyclic aromatic hydrocarbons in the air. PhD thesis. Katowice: University of Silesia

Yang X, Yin Y, Zong Y, Wan T, Liao X (2019) Magnetic nanocomposite as sorbent for magnetic solid phase extraction coupled with high performance liquid chromatography for determination of polycyclic aromatic hydrocarbons. Microchem J 145:26-34

Zhao T, Yang L, Huang Q, Zhang W, Duan S, Gao H, Wang W (2020a) Polycyclic aromatic hydrocarbons (PAHs) and nitrated-PAHs (NPAHs) emitted by gasoline vehicles: Characterization and health risk assessment. Sci Total Environ 727:138631

Zhao T, Yang L, Huang Q, Zhang Y, Bie S, Li J, Zhang W, Duan S, Gao H, Wang W (2020b) PM2.5-bound polycyclic aromatic hydrocarbons (PAHs) and their derivatives (nitrated-PAHs and oxygenatedPAHs) in a road tunnel located in Qingdao, China: Characteristic, sources and emission factors. Sci Total Environ 720:137521

Zielinska B, Sammy S (2006) Analysis of nitrated polycyclic aromatic hydrocarbons. Anal Bioanal Chem 386:883-890

Publisher's Note Springer Nature remains neutral with regard to jurisdictional claims in published maps and institutional affiliations. 